\title{
ENVIRONMENTAL AND SOCIO- ECONOMIC FACTORS AS DRIVERS OF TUBERCULOSIS IN NIGERIA: PARADIGM TO ADOPT MATHEMATICAL APPROACH FOR RESEARCH AND INTERVENTION.
}

\author{
${ }^{1}$ Aliyu Abubakar Shehu, ${ }^{2}$ Onwuka Gerald Ike, ${ }^{3}$ Abdullahi Bako Rabah, ${ }^{4}$ Nasiru Lawal \\ ${ }^{1}$ Save the Nature Foundation, Sokoto, Nigeria, ${ }^{2}$ Department of Mathematic and Statistics, \\ Kebbi State University, Aleiro, Nigeria ${ }^{3}$ Department of Microbiology, Usmanu Danfodiyo \\ University, Sokoto, Nigeria, ${ }^{4}$ School of Postgraduate, Nigerian Defence Academy, Kaduna, \\ Nigeria
}

\begin{abstract}
As the trend of globalization is increasing due to population growth, climate change and another social factor, it continues to increase vulnerability of many diseases. Tuberculosis $(T B)$ disease remains one of the prevalent communicable diseases globally Its significant rate in developing countries like Nigeria has remains a fascinating global public health concern due to public health and economics posed by the disease. This paper reviewed environmental and socio-economic factors affecting the prevalence; surveillance of TB from authoritative journal articles, grey reports, as well as other official and authoritative sources. The study found the connection between environmental; socio-economic factors and prevalence and surveillance of TB in Nigeria. At the of study six (6) recommendations such as; education and awareness; online diseases reporting and notification; research priorities; use of mathematical models; inclusive provision of health facilities as well as partnership and collaboration were put forward in relation to environmental and socio-economic factors and trends.
\end{abstract}

KEYWORDS; Environment, Mathematical, Nigeria, Socio- Economic, Surveillance Tuberculosis 


\subsection{Background}

Tuberculosis is a communicable, bacterial disease caused by Mycobacterium tuberculosis. It spreads from one person to another through inhalation of air droplets (Centre for Disease Control (CDD, 2011).

The pathological cycle of the disease is presented in Figure 1.

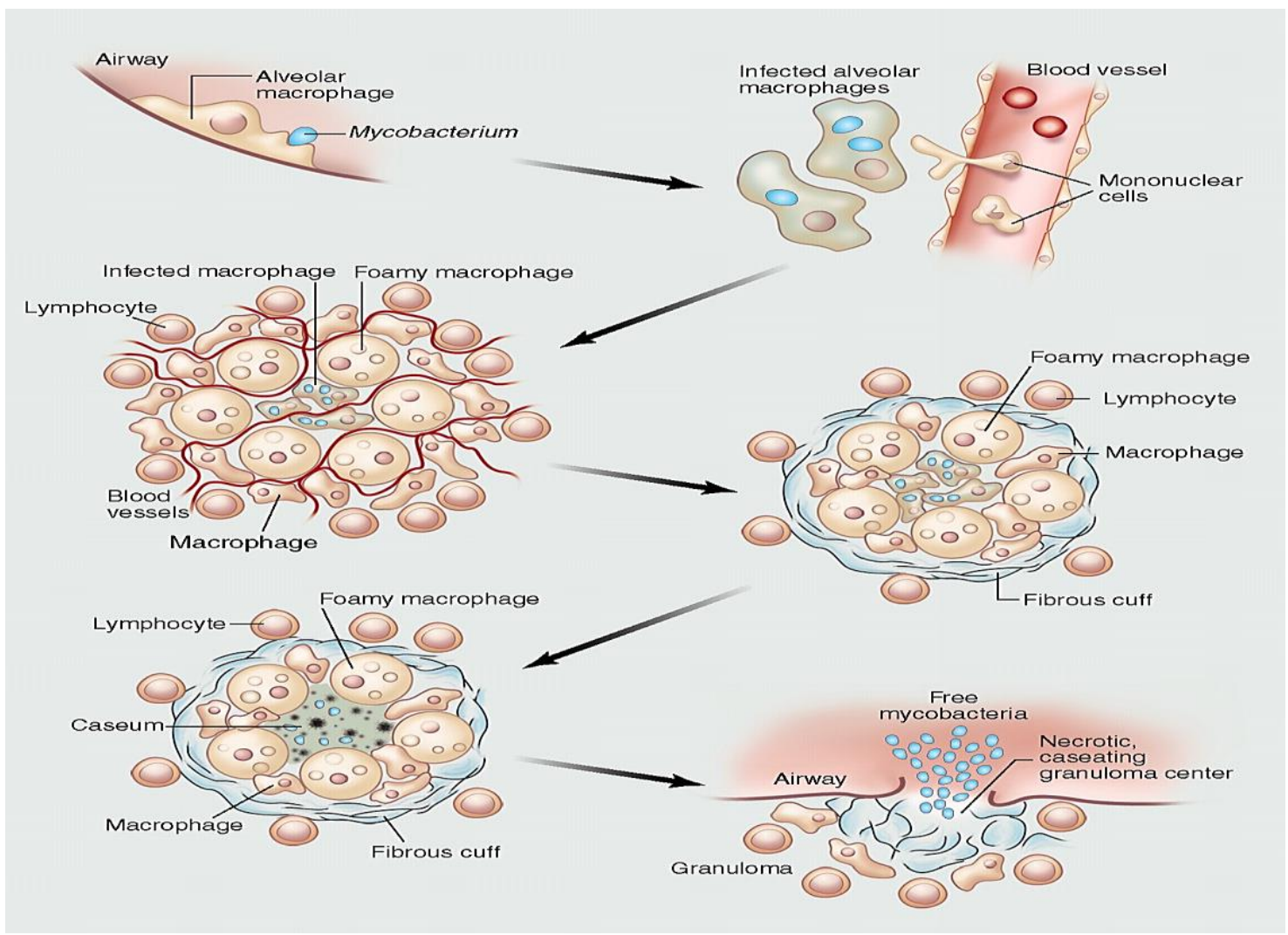

Figure 1: Pathological cycle of Tuberculosis disease (Russell, Barry \& Flynm 2010)

An authoritative statistic on the global burden of TB published by World Health Organisation (WHO) in 2018 shows, that of the ten (10) million infected with TB globally, 1.6 million mortality from the disease was recorded in 2017 (WHO, 2018). Moreover, about 104,904 cases of the disease were reported in 2017, with 102,387 new relapsed cases of the disease in Nigeria (WHO, 2018).

In Nigeria the control of TB is coordinated by Nigeria's National Tuberculosis and Leprosy Control Program (NTBLCP). Although, there also governmental and non-governmental organisation that are working towards eradication, control and management diseases, TB remains one of the major causes of mortality and morbidity causing diseases across age ranges in Nigeria (Amadi et al., 2019; Ogbuabor, \& Onwujekwe, 2019). Nigeria's NTBLCP targets to eliminate TB in the country to less than 1 case per 1,000000 population by the www.ijrp.org 
(Ahmad et al., 2018). This target could be achieved but for the many hitches hindering the agency's success. An active surveillance system will be a vital tool in addressing these problems generally in Public health. Surveillance is non-stop, orderly collection, investigation, and interpretation of the outbreaks of diseases and the disease-related factors (Weizhong \& $\mathrm{Li}$, 2017). Thus, effective surveillance is not tool for detection of the disease, but also guides budgeting and allocation of resources towards epidemiological surveillance and control of plants, zoonotic and human diseases (Parnell et al., 2017: Rees et al., 2019; Yemshanov et al., 2019; Mandal et al., 2020). Thus, spatial approach can be considered as modern effective and cost-effective way of informing surveillance strategy towards prevention, control and management of diseases (Plant, zoonotic and human diseases). It is therefore vital in helping nations monitor and assess emerging patterns and trend of the diseases, and thus, contributes to better prevention and management of diseases.

\subsection{Environmental and Socio- Economic Factors as Tuberculosis Drivers}

Transmission of tuberculosis is triggered by environmental conditions like the flow of contaminated air droplets (Andrews et al., 2017). This gives the perfect conditions for airborne particles containing M. tuberculosis to stay viable. Additionally, Andrews et al., (2017) indicate that humidity also impacts on the settling and vanishing of the droplets. Consequently, it thus increases the risk of tuberculosis. Other factors such as smoking, high alcohol consumption and malnutrition, and host's health status such as diabetes, HIV /AIDs patients, may expand a person's vulnerability of movement to active pulmonary infection of TB and contacts with the TB patient (Andrews et al., 2017). These factors can influence behavioral and socio-economic status.

The factors mentioned earlier are common in Nigeria. As a result, it replicates in the report of Cadmus et $a l .$, (2018) where Nigeria is rated fourth among the countries with the highest burden of TB. Similarly, Ogbo et al., (2018) reported prevalence trends of TB in Nigeria to be 158 in 100,000 people, and the total number of TB attributable deaths was 39,933 in 2016.

The prevalence of tuberculosis in Nigeria is shown in figure 2. 


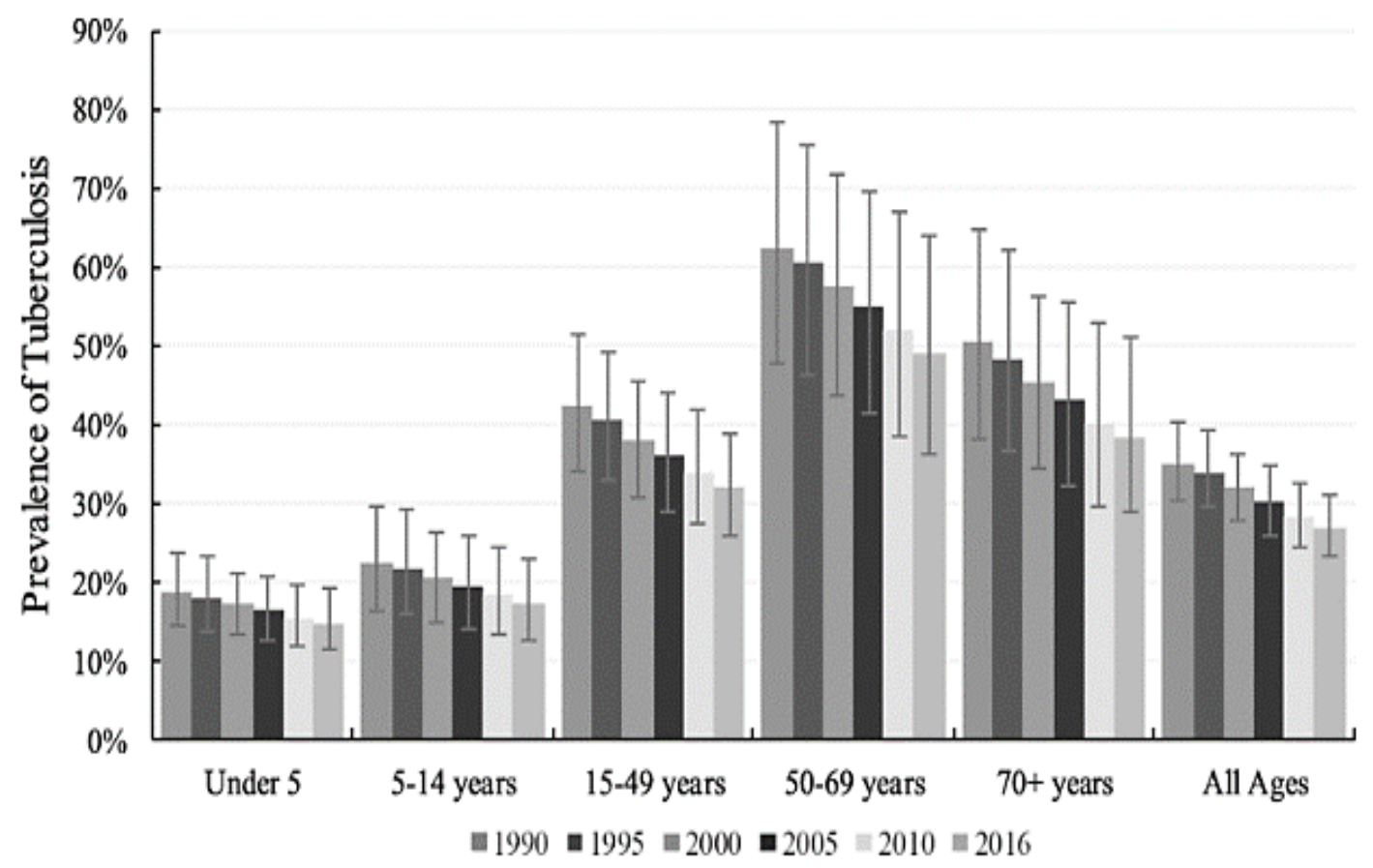

Figure 2: Annual prevalence of occurrence of TB among age groups in Nigeria between 1990 and 2016 (Ogbo et al. 2018)

Figure 2 displays the highest prevalence among the people aged between 50 to 69 years and lowest among the children below five years of birth. Perhaps, the 50 to 69 age group could be the stage where the accumulation of behaviour manifests as TB.

The prevalence trends of TB in Nigeria were 158 in 100,000 people, and the total number of TB attributable deaths was 39,933 in 2016 (Ogbo et al., 2018). This study further shows decreases in prevalence and death cases from 2000 to 2016 in the country, but disease resurgence is also shown in figure 2 . This could be due to factors such as population growth, urbanisation, improper management, changes in the weather and climate due to the climate change and socio-economic inequalities as these are TB determinants and are also high in Nigeria (Lasebikan \& Ige, 2016).

According to a research conducted by Nicole et al (2012) on socio-economic status and tuberculosis rates by country of birth in the United States. The research tends to determine the association of socio-economic status (SES) with rate of TB in U.S. born and Foreign-born persons in the United States. Findings of the research shows that rates of TB were highest in the quartiles with low SES for both US born and Foreign-born populations. Multivariate analysis shows strong association between TB and all the four (4) indicators of SES. Crowding, poverty, occupation, lifestyle and unemployment had strongest association with TB rates. 
In a related connection, recent research conducted by Jiamsakul et al., (2020). On the socioeconomic status and risk of TB. A case-control study of HIV infected patients in Asia shows that SES continue to influence to TB incidence both resource rich and resource poor settings.

A comparative analysis by (Jiamsakul et al., 2020) stated that in sub-saharan Africa, low education level, unemployment, low income, poverty smoking and alcohol use and being single have shown strong association with TB. Low SES background can contribute to an increased risk of TB and unfavorable TB treatment outcomes. Matched pair analysis shows significant increase of TB with with education level below University.

Dheeraj et al., (2004). Used level of income, level of education, crowding, water supply, type of housing and number of consumer items such as refrigerator, television, radio as socioeconomic variables influencing prevalence of Tuberculosis in Chandigarh, India.

Demographics results shows patients with 35.5 years àre more vulnerable to the impacts of Tuberculosis and the disease is more pronounced in men $(67.2 \%)$ than in women $(32.8 \%)$. Dheeraj et al., (2004).

Patients with lower SES were more vulnerable to cases of TB. Dheeraj et al., (2004). Multivariate logistic regression analysis shows that only age, level of education, crowding, type of housing, water supply and number of consumer articles in the household were found to be independently and significantly associated with high risk of Tuberculosis. These translates the strong connection between environmental, socio economic factors and the spread of TB.

Also, the same pattern of decreasing burden is observed in the mortality trends is shown in

\section{figure 3.}

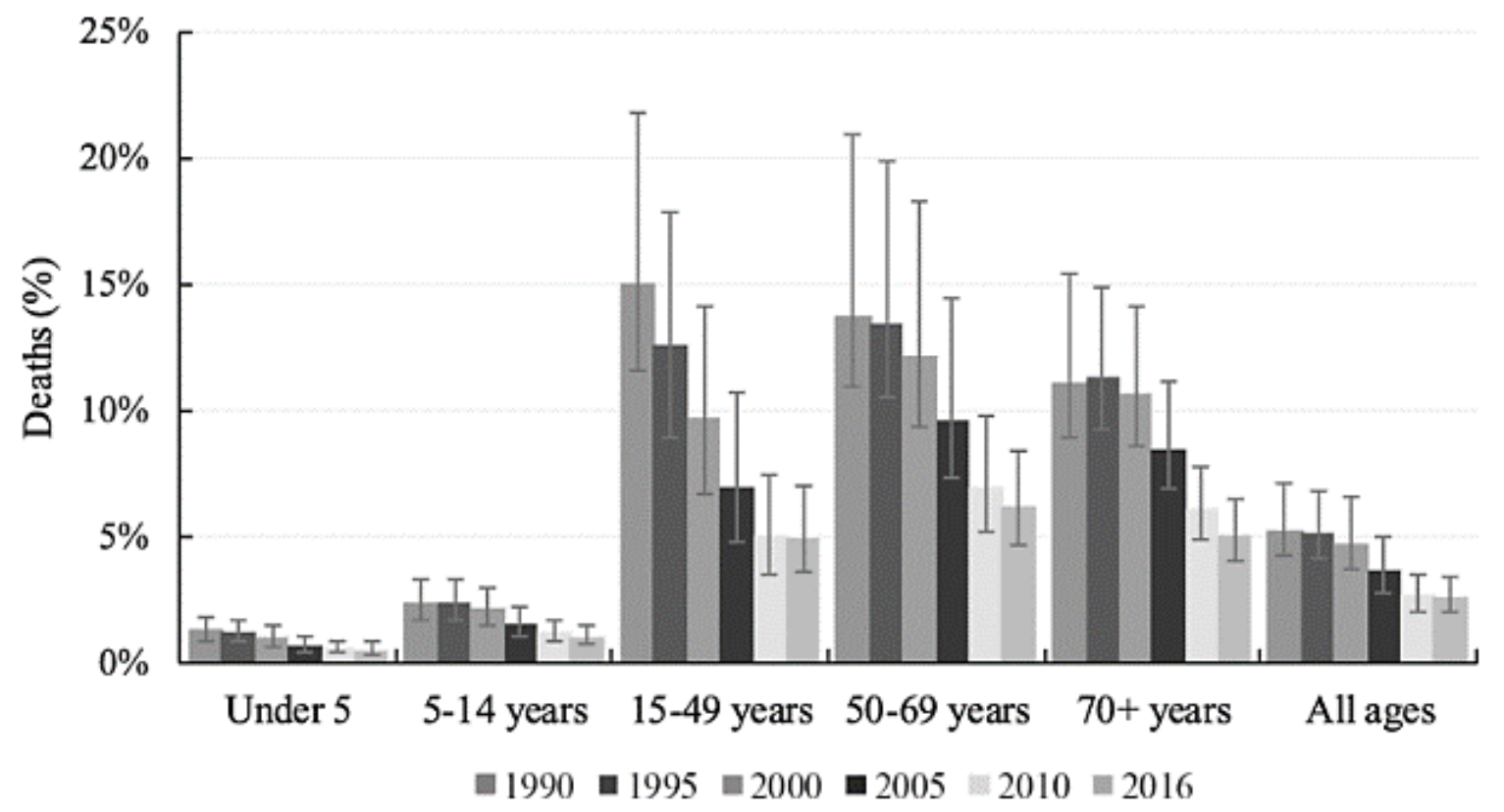

Figure1. 3: Annual deaths cases from TB by age in Nigeria Between 1990 and 2016 (Ogbo et al. 2018) 
Figure 2 and 3 shows the decrease in TB prevalence and mortality from 1990 to 2016 in Nigeria though, with fluctuations in years. The burden of tuberculosis in Nigeria is significant having $5 \%$ of overall global incidences (Ogbo et al. 2018)

Table 1 also shows the annual TB incidence in Nigeria per 100,000 people from 1990 to 2016. The annual TB mortality from by age (with 95\% uncertainty interval, UI) in Nigeria from 1990 to 2016 is shown in Table 1.

\begin{tabular}{|c|c|c|c|c|c|c|c|}
\hline \multirow[t]{2}{*}{ Age } & 1990 & 1995 & 2000 & 2005 & 2010 & 2016 & \multirow{2}{*}{$\begin{array}{l}\text { \% change } \\
\text { (1990 } \\
-2016)\end{array}$} \\
\hline & $\begin{array}{l}\text { N }(95 \% \\
\text { UI) }\end{array}$ & $\begin{array}{l}\text { N }(95 \% \\
\text { UI) }\end{array}$ & $\begin{array}{l}\text { N }(95 \% \\
\text { UI) }\end{array}$ & $\begin{array}{l}\text { N }(95 \% \\
\text { UI) }\end{array}$ & $\begin{array}{l}\text { N }(95 \% \\
\text { UI) }\end{array}$ & $\begin{array}{l}N(95 \% \\
\text { UI) }\end{array}$ & \\
\hline $\begin{array}{l}\text { Under } \\
5 \text { years }\end{array}$ & $\begin{array}{l}218(153 \\
-306)\end{array}$ & $\begin{array}{l}226(156 \\
-323)\end{array}$ & $\begin{array}{l}220(150 \\
-317)\end{array}$ & $\begin{array}{l}179(122 \\
-264)\end{array}$ & $\begin{array}{l}136(91 \\
-199)\end{array}$ & $\begin{array}{l}102(71 \\
-148)\end{array}$ & $-53 \cdot 3$ \\
\hline 5-14 years & $\begin{array}{l}68(43 \\
-100)\end{array}$ & $\begin{array}{l}71(45 \\
-106)\end{array}$ & $\begin{array}{l}78(48 \\
-117)\end{array}$ & $\begin{array}{l}77(47 \\
-117)\end{array}$ & $\begin{array}{l}65\left(3^{8}\right. \\
-102)\end{array}$ & $\begin{array}{l}56(34 \\
-85)\end{array}$ & -16.9 \\
\hline $\begin{array}{l}15 \\
-49 \text { years }\end{array}$ & $\begin{array}{l}356(273 \\
-461)\end{array}$ & $\begin{array}{l}377(273 \\
-497)\end{array}$ & $\begin{array}{l}358(254 \\
\left.-4^{8} 7\right)\end{array}$ & $\begin{array}{l}290(201 \\
-400)\end{array}$ & $\begin{array}{l}228(161 \\
-312)\end{array}$ & $\begin{array}{l}210(155 \\
-274)\end{array}$ & -41.1 \\
\hline $\begin{array}{l}50 \\
-69 \text { years }\end{array}$ & $\begin{array}{l}536(399 \\
-699)\end{array}$ & $\begin{array}{l}55^{8}\left(39^{8}\right. \\
-742)\end{array}$ & $\begin{array}{l}557(377 \\
-773)\end{array}$ & $\begin{array}{l}474(321 \\
-669)\end{array}$ & $\begin{array}{l}354(235 \\
-506)\end{array}$ & $\begin{array}{l}276(182 \\
-396)\end{array}$ & $-4^{8.6}$ \\
\hline $70+$ years & $\begin{array}{l}799(591 \\
-1045)\end{array}$ & $\begin{array}{l}807(601 \\
-1073)\end{array}$ & $\begin{array}{l}759(543 \\
-1007)\end{array}$ & $\begin{array}{l}607(428 \\
-821)\end{array}$ & $\begin{array}{l}425(304 \\
-574)\end{array}$ & $\begin{array}{l}342(244 \\
-464)\end{array}$ & -57.2 \\
\hline All ages & $\begin{array}{l}277(233 \\
\left.-3^{29}\right)\end{array}$ & $\begin{array}{l}292(240 \\
-356)\end{array}$ & $\begin{array}{l}285(228 \\
-352)\end{array}$ & $\begin{array}{l}236(188 \\
-293)\end{array}$ & $\begin{array}{l}182(146 \\
-231)\end{array}$ & $\begin{array}{l}158(128 \\
-193)\end{array}$ & -42.9 \\
\hline
\end{tabular}

Table 1. Annual TB incidence in Nigeria per 100,000 population with $95 \%$

Annual TB mortality by from by age (with 95\% uncertainty interval (UI) from 1990 to 2016 shown in table 2. 


\begin{tabular}{|c|c|c|c|c|c|c|c|}
\hline \multirow[t]{2}{*}{ Age } & 1990 & 1995 & 2000 & 2005 & 2010 & 2016 & \multirow{2}{*}{$\begin{array}{l}\% \\
\text { change } \\
\text { (1990 } \\
\text {-2016) }\end{array}$} \\
\hline & $\begin{array}{l}N(95 \% \\
\text { UI) }\end{array}$ & $\begin{array}{l}N(95 \% \\
\text { UI) }\end{array}$ & $\begin{array}{l}N(95 \% \\
\text { UI) }\end{array}$ & $\begin{array}{l}N(95 \% \\
\text { UI) }\end{array}$ & $\begin{array}{l}N(95 \% \\
\text { UI) }\end{array}$ & $\begin{array}{l}N(95 \% \\
\text { UI) }\end{array}$ & \\
\hline $\begin{array}{l}\text { Under } \\
5 \text { years }\end{array}$ & $\begin{array}{l}9313 \\
(5939 \\
-13,651)\end{array}$ & $\begin{array}{l}9557 \\
\left(613^{6}\right. \\
\left.-14,35^{6}\right)\end{array}$ & $\begin{array}{l}8577 \\
(5421 \\
-13,213)\end{array}$ & $\begin{array}{l}5868 \\
(3733 \\
-8747)\end{array}$ & $\begin{array}{l}3519 \\
(2148 \\
-5743)\end{array}$ & $\begin{array}{l}4720 \\
(3030 \\
-7196)\end{array}$ & $-49 \cdot 3$ \\
\hline $\begin{array}{l}5 \\
-14 \text { years }\end{array}$ & $\begin{array}{l}13^{82}(964 \\
-1926)\end{array}$ & $\begin{array}{l}1517(1055 \\
-2095)\end{array}$ & $\begin{array}{l}1447(981 \\
-1975)\end{array}$ & $\begin{array}{l}1113(756 \\
-1572)\end{array}$ & $\begin{array}{l}746(503 \\
-1060)\end{array}$ & $\begin{array}{l}875 \text { (6oo } \\
-1211)\end{array}$ & -36.7 \\
\hline $\begin{array}{l}15 \\
-49 \text { years }\end{array}$ & $\begin{array}{l}21,542 \\
(16,162 \\
-31,474)\end{array}$ & $\begin{array}{l}24,437 \\
(17,214 \\
-34,397)\end{array}$ & $\begin{array}{l}25,107 \\
(16,951 \\
\left.-37,3^{81}\right)\end{array}$ & $\begin{array}{l}20,300 \\
(13,190 \\
-30,585)\end{array}$ & $\begin{array}{l}12,187 \\
(8543 \\
-17,420)\end{array}$ & $\begin{array}{l}13,916 \\
(9311 \\
-20,530)\end{array}$ & -35.4 \\
\hline $\begin{array}{l}50 \\
-69 \text { years }\end{array}$ & $\begin{array}{l}18,723 \\
(14,227 \\
-27,847)\end{array}$ & $\begin{array}{l}21,405 \\
(15,544 \\
-31,463)\end{array}$ & $\begin{array}{l}22,178 \\
(15,703 \\
-32,747)\end{array}$ & $\begin{array}{l}17,871 \\
(12,701 \\
-26,285)\end{array}$ & $\begin{array}{l}10,573 \\
(7688 \\
-1,4845)\end{array}$ & $\begin{array}{l}12,357 \\
(8797 \\
-17,817)\end{array}$ & -34 \\
\hline $70+$ years & $\begin{array}{l}11,553 \\
(9091 \\
-15,539)\end{array}$ & $\begin{array}{l}13,613 \\
(10,740 \\
-17,887)\end{array}$ & $\begin{array}{l}14,034 \\
(10,930 \\
-18,725)\end{array}$ & $\begin{array}{l}11,274 \\
(8711 \\
-14,819)\end{array}$ & $\begin{array}{l}7377 \\
(5655 \\
-9722)\end{array}$ & $\begin{array}{l}8065 \\
(6129 \\
-10,550)\end{array}$ & -30.2 \\
\hline All ages & $\begin{array}{l}62,513 \\
(50,969 \\
-85,245)\end{array}$ & $\begin{array}{l}70,530 \\
(54664 \\
-94,278)\end{array}$ & $\begin{array}{l}71,343 \\
(54,497 \\
-98,715)\end{array}$ & $\begin{array}{l}56,427 \\
(42,423 \\
-77,678)\end{array}$ & $\begin{array}{l}34,403 \\
(26,533 \\
-46,550)\end{array}$ & $\begin{array}{l}39,933 \\
(30,488 \\
-55,039\end{array}$ & $-3^{6.1}$ \\
\hline
\end{tabular}

Table 2. Annual TB mortality from by age (with $95 \%$ uncertainty interval, UI) in Nigeria from 1990 to 2016 (Ogbo et al. 2018).

Table 1 and 2 translates the significant burden of TB in Nigeria, which could also affect economic of the country.

\subsection{Economic Impacts of Tuberculosis}

Apart from epidemiological burden, TB is also a threat to the global economy, over US\$ 6.9 billion spent on the disease in 2018 (WHO, 2018). Also, in 2014 African countries lost $1.37 \%$ of their combined GDP because of the 753423 TB deaths (Kirigia \& Muthuri, 2017). In Nigeria TB patients faces indirect expenses from loss of income, considerable out-of-pocket expenses for transport and nutritional supplementation (Ukwaja et al., 2017).

\subsection{National TB Surveillance}

The strategy used for surveillance of Tuberculosis disease in Nigeria is the Integrated Disease Surveillance and Response (IDSR), it was established and implemented in 1998 for SubSaharan Africa as the comprehensive regional public health approach (Aruna et al., 2018). Afterwards, the country approved the IDSR Technical Procedures, which showcased 
operations and procedures for reporting significant diseases, as well as improving universal access to TB diagnosis and treatment through the strategic increase of facilities (Aruna, Nsofor, \& Oyediran, 2018). However, the system is used for the surveillance of TB together with 40 communicable and non-communicable diseases (Aruna, Nsofor, \& Oyediran, 2018). IDSR is used as country's system of identification and notification of TB cases, a local TB identifying officer is assigned by the local government focal officer (Ershova, 2013). The total number 94,604 are covered, about 70,858 tuberculosis cases were reported across 774 Local Government Areas in the country through IDSR surveillance (Obasanya et al., 2015).

Despite the success recorded, IDSR has loopholes. For instance, Phalkey et al. (2018) finds poor knowledge health personnel and local TB reporting officers, inadequate coordination, and delay in response. Other barriers to IDSR include non-accountability, failure to follow obligatory reporting order (Arua, Nsofor \& Oyediran, 2018).

\section{3 Collaborative Surveillances}

Ministry of Health through the National Tuberculosis and Leprosy Control Programme is collaborating with international development partners to carry out TB surveillance in Nigeria (Nasir et al., 2015). This involve providing operational guidelines to the health personnel, and medical equipment such as mobile x-rays, laboratory reagents (Nasir et al., 2015). But is affected by factors such as inadequate skills and communication, poor internet connection in rural areas, language and cultural barriers as well as inadequate monitoring (Nasir et al., 2015). In 2015 , the United Nations recommended Sustainable Development Goals (SDGs), that incorporated WHO's End TB Strategy of ending the TB prevalent by the year 2030 ( Uplekar et al. 2016).It is set to reduces $80 \%$ TB incidence and $90 \%$ of TB related deaths by the year 2030 (Medecins Sans Frontieres, 2017).

Moreover, developed countries like United Kingdom (UK) and Australia make the TB testing compulsory, at Migration Health Assessment Centre for any residents of with high TB case like Nigeria entering the country six months before entering the countries like UK (Uplekar et al. 2016). However, this enhanced disease notification and detection, it could be limited due to the shortage of health workforce.

\subsection{TB Referrals Surveillances Models.}

Other model used for TB surveillance in Nigeria, for instance, Adejumo et al. (2016) used four different models to boost and compare the different models for TB surveillance in three most highly dense TB states in the country (Lagos, Oyo, and Abia State). The models used, which 
are community compensation, use direct dealing model that involves health workers supervision and meeting with traditional rulers, supervision without quotas, comprehensive quotas method and unsupervised volunteer that involve supervision of community workers.

The end TB initiative initiated new diagnostic testing. This placed emphasis on the accuracy, rapid growth detection, simplicity and reliability of possible TB detection globally (Dorman, 2010). The test is done by the collection of three sputum samples for testing diagnosis and two for follow-up diagnostic confirmation, furthermore HIV patients are subjected to Extrapulmonary TB (Dorman, 2010).

In Nigeria, there is an increase in the TB surveillance with technological advancements and tightening efforts of syndromic notification of disease in the country. There is a high proportion of undiagnosed TB patients in the country, which is a considerable obstacle for achieving the target of less than $1 \mathrm{~TB}$ case per one million population in the country by the year 2050 (Ahmad, 2018). The central government have an ethical obligation to implement services and ensure confidentiality with patients privacy and data protection based on the WHO policy of handling TB endemic (Medecins Sans Frontieres, 2017). Moreover, compliances with the standard relate to loopholes, as many patient's inability to communicate in the clinics and overcrowding of patients due to inadequate facilities especially in rural health care centres (Kuyinu et al., 2016)

\subsection{Biosafety level 3 (BSL-3) Surveillance}

The US President's Emergency Plan for AIDS Relief(PEPFAR) program, donated the modular BSL-3 bio-surveillance laboratories to Nigeria's TB program (Aliyu et al., 2017). This helped in diagnosing the disease. As of 2017, the laboratories tested 11,606 suspected cases tested for resistant TB using sputum samples, 1500 were identified with mono-resistance TB and 459 with multi-resistance TB (Aliyu et al., 2017).

\subsection{Latent TB Screening}

Developed nation conduct latent tuberculosis screening for immigrants using interferongamma release test or tuberculin skin examinations (Pareek et al., 2016). Some countries in the Western do test the passengers immediately an arrival, but some like the UK certify the visitors before issuance of visa entry to the country, while the immigrants' test abnormal with negative sputum cultures are subjected to treatment before arrival or surveillance after arrival (Pareek et al., 2016). 


\subsection{Findings and Discussion}

This review finds out that, problems such as (1) Fear of stigmatization and inadequate awareness on Tuberculosis (2) Data and Reporting Reliability (3) Inadequate Human Resource and Facilities as well as (4) complexity in Nigerian Surveillance System as discuss below;

\subsection{Fear of stigmatization and inadequate awareness on Tuberculosis}

Inadequate people's knowledge and awareness on the early signs and diagnosis of TB could be attributable factor leading to significant mortality and morbidity of TB Chinnakali et al., 2013; Joshi et al., 2019; Chen et al., 2019). Moreover, TB patients could be diagnosed at the critical stages, which can consequently lead to the non-survival of some patients. This, perhaps, could be due to fear of being labelled as TB carrier.

In a related development, recent study identified stigmatization as a serious problem hindering the success of fights against TB in Nigeria (Balogun et al., 2015). Also, significant similarities of TB with HIV/AIDs could also be considered to be a barrier, since misconception factor influences population nonparticipation in testing. Most critical of the stigma could be confidentiality of TB patient's data and identity. Ibrahim et al., (2014), which could be connected with stigma factor.

\subsection{Data and Reporting Reliability}

Surveillance data obtained from clinics and dispensaries are manually transferred to national tuberculosis and leprosy head office through the Local government and state offices (Onyeonoro et al., 2015). This could significantly affect the validity, effectiveness and feedback of the surveillance of TB. Thus, affect intervention, policy and distribution of services. Manual entry and transfer of data create a higher window of error. Moreover, it may also have some ethical limitations by transfer of patients /community information and privacies.

\subsection{Inadequate Human Resource and Facilities}

There is lack of/improper coordination for Tuberculosis surveillance among the health workers in the rural areas of the country, which was attributable to inadequately skilled health Pareek et al., 2016; Zenner et al. 2018). Likewise, many patients cover long distances to reach health care centres. 


\subsection{The complexity of the Surveillance System}

The Integrated Disease Surveillance and Response (IDSR) adopted in Nigeria for the surveillance of 41 diseases is functional generally. However, it has no clear framework on tuberculosis; that is why over $80 \%$ of Tuberculosis cases are still undetected. This system has no emphasis on the spatial system of surveillance.

\subsection{Conclusion /Recommendations for further Actions}

Even with the efforts put in eradicating TB, Nigeria is among the countries with the high rate of tuberculosis cases in the global indices due to environmental and socio- economic factors and TB as communicable diseases is continuously posing huge burden to the country's health and economic sectors. However, there is dire need to address challenges hindering detection, control and management of tuberculosis and other diseases. The following recommendations were put for further actions and intervention.

\subsection{Recommendations for Further Actions}

1. Government and other relevant stakeholders should develop a robust and sustainable platform for educating, enlightening the populace on tuberculosis. Additionally, there is need for training and retraining of health workers so as to promote professional ethic and workplace particularly $\mathrm{TB}$ centres and thus, minimise the problem of stigmatization among TB patients through seminars, workshops, dialogue and scholarship schemes.

2. Online surveillance database should be developed for reporting Tuberculosis in the country. This will reduce feedback delays, ensure reliability and data confidentiality in the country. Furthermore, the ministry of health should collaborate with Nigerian Airspace Agency and meteorological agency to develop spatial surveillance models using GIS and remote sensing. This could provide a proper technique of TB surveillance for detection of the disease even before hospital administration and can predict socioeconomic trends of the diseases (Beiranvand et al., 2016; Daniel, (2017)). This will have less ethical limitations and may not require human resource as GIS, and remote sensing tools will be used.

3. Research and development innovations will pave the way for the policymaker to evaluate, review and improve sustainable surveillance, prevention and control of TB 
in the country. It, however, should be per socio economic factors of geopolitical zones of the country.

4. Mathematical approaches such as rule of three binomial are used to inform surveillance strategy and allocation of resource (Parnell et al., 2017; Bourhis et al., 2019; Jahanbin et al., 2018). Spatial approaches can be employed to improve the surveillance of TB. However, spatial models need to be employed in general public health system for prevention, control and management of disease emergence.

5. Government should urgently address facilities and health workforce shortages at all level by ensuring equitable universal health care coverage in the country.

6. Nigeria should collaborate with African countries primarily West African nations to enact migration and urbanisation laws and policies. Rapid urbanisation and migration hinder TB surveillance and control in Nigeria (Kanayo et al., 2013). The government should collaborate with traditional and religious institutions to create a platform for awareness and reporting of TB cases in the country. Moreover, enabling laws should be enacted for the protection of patient's privacy and reduction of stigmatisation.

\subsection{DECLARATION}

The authors of this paper declare no conflict of interest in this paper. 


\section{References}

Adejumo, A. O., Azuogu, B., Okorie, O., Lawal, O. M., Onazi, O. J., Gidado, M., Mitchell, M. E. (2016). Community referral for presumptive TB in Nigeria: a comparison of four models of active case finding. BMC Public Health, 16(177). Retrieved 04 08, 2019, from https://bmcpublichealth.biomedcentral.com/articles/10.1186/s12889-016-2769-7

Ahmad, N. M., Montañola-Sales, C., Prats, C., Musa, M., López, D., \& Casanovas-Garcia, J. (2018). Analysing Policymaking for Tuberculosis Control in Nigeria. Hindawi Complexity, 1-17. $\quad$ Retrieved $04 \quad 01, \quad 2019$, from https://www.hindawi.com/journals/complexity/2018/9253846/

Aliyu, G., Ezati, N., Iwakun, M., Peters, S., \& Abimiku, A. (2017). Diagnostic system strengthening for drug-resistant tuberculosis in Nigeria: impact and challenges. African Journal of Laboratory Medicine, 6(2). Retrieved 04 05, 2019, from https://www.ncbi.nlm.nih.gov/pmc/articles/PMC5523970/

Amadi, C., Carrillo, P., \& Tuuli, M. (2019). PPP projects: improvements in stakeholder management. Engineering, Construction and Architectural Management

Andrews, J. R., Cohen, J., Borgdorff, M., Behr, M., Glynn, J. R., Rustomejee, R., Wood, R. (2017). Drivers of Tuberculosis Transmission. The Journal of Infection Diseases, 216(6,1), 644-653. doi:10.1093/infdis/jix354

Aruna, O., Nsofor, I., \& Oyediran, K. (2018, 09). Tuberculosis in Nigeria: Rapid Assessment of Infectious Disease Surveillance and Reporting. Retrieved 03 28, 2019, from MEASUREMENT

Evaluation: https://www.measureevaluation.org/resources/publications/tr-18-292/

Balogun, M., Sekoni, A., Meloni, T., Odukoya, O., Onajole, A., Longe, O., . . Kanki, P. J. (2015). Trained Community Volunteers Improve Tuberculosis Knowledge and Attitudes Among Adults in a Periurban Community in Southwest Nigeria. American Journal of Tropical Medicine and Hygiene, 92(3),. 625-632. Retrieved 04 10, 2019, 
from

www.ajtmh.org/docserver/fulltext/14761645/92/3/625.pdf?expires=1554841191\&id=i $\mathrm{d} \&$ accname=guest $\&$ checksum $=4 \mathrm{~F} 1 \mathrm{E} 7 \mathrm{E} 475 \mathrm{~B} 5647 \mathrm{E} 9 \mathrm{C} 8 \mathrm{~F} 65735 \mathrm{DA} 4 \mathrm{E} 78 \mathrm{AA}$

Beiranvand, R., Karimi, A., Delpisheh, A., Sayehmiri, K., Soleimani, S., \& Ghalavandi, S. (2016). Correlation assessment of climate and geographic distribution of tuberculosis using a geographical information system (GIS). Iranian journal of public health, 45(1), 86.

Bourhis, Y., Gottwald, T. R., Lopez-Ruiz, F. J., Patarapuwadol, S., \& van den Bosch, F. (2019).

Sampling for disease absence-deriving informed monitoring from epidemic traits.

Journal of theoretical biology, 461, 8-16.

BMC. (n.d.). Prevalence of drug-resistant tuberculosis in West Africa higher than previously thought. Retrieved 04 02, 2019, from BMC: https://www.biomedcentral.com/about/press-centre/science-press-releases/3-11-16

Cadmus, S. I., Falodun, O. I., Fagade, O. E., Murphy, R., Taiwo, B., \& Soolingen, V. D. (2018). The problem of resistance in Mycobacterium tuberculosis may be underestimated in Africa. International Journal of Mycobacteriology, 7(2), 148-151. doi:10.4103/ijmy.ijmy_29_18

Centres for Disease Control and Prevention (CDC). (2011). Tuberculosis. Retrieved 03 22, 2019, from CDC: https://www.cdc.gov/tb/publications/factsheets/general/tb.htm

Chinnakali, P., Ramakrishnan, J., Vasudevan, K., Gurumurthy, J., Upadhyay, R. P., \& Panigrahi, K. C. (2013). Level of awareness about tuberculosis in urban slums: Implications for advocacy and communication strategy planning in the National program. Lung India: official organ of Indian Chest Society, 30(2), 139.

Chen, X., Wang, W., Wang, X., Chai, C., Liu, K., Peng, Y., ... \& Jiang, J. (2019). Public Awareness of Tuberculosis in Southeast China: A Population-Based Study. International journal of environmental research and public health, 16(21), 4290.

Daniel, O., 2017. Spatial distribution of tuberculosis in Nigeria and its socioeconomic correlates (Doctoral dissertation, Lancaster University).

Dorman, S. (2010). New Diagnostic Tests for Tuberculosis: Bench, Bedside, and Beyond.
Clinical
Infectious
Diseases,
50
(3),
173-177. doi:https://academic.oup.com/cid/article/50/Supplement_3/S173/318342 
Ershova, J. (2013). Assessment of the performance of TB surveillance in Nigeria main findings, key recommendations and associated investment plan. Retrieved 04 01, 2019, from WHO:

https://www.who.int/tb/advisory_bodies/impact_measurement_taskforce/meetings/acc ra2013_3_checklist_nigeria_ershova.pdf

Gupta, Dheeraj \& Das, Kshaunish \& Balamugesh, Thangakunam \& Agarwal, Anant \& Jindal, Surinder. (2004). Role of socio-economic factors in tuberculosis prevalence. Indian J Tuberc. 51. 27-31.

Ibrahim, S. A., Hamisu, I., \& Lawal, U. (2015). The spatial pattern of tuberculosis prevalence in Nigeria: a comparative analysis of spatial autocorrelation indices. Am J Georg Infor System, $4(3), 87-94$

Ibrahim, L. M., Hadejia, I. S., Nguku, P., Dankoli, R., Waziri, A. M., Oyemakinde, O. S., \& Nwanyanwu, D. I. (2014). Factors associated with interruption of treatment among Pulmonary Tuberculosis patients in Plateau State, Nigeria. 2011. The Pan African Medical Journal, 17(78). Retrieved 04 11, 2019

Jahanbin, K., Rahmanian, F., Rahmanian, V., \& Jahromi, A. S. (2019). Application of Twitter and web news mining in infectious disease surveillance systems and prospects for public health. GMS Hygiene and Infection Control, 14

Joshi, J. L., Abraham, J., Bhatnager, A., Chungath, J. T., Girdhar, N., Bharti, A., ... \& Sharma, K. (2019). Reducing the burden of Tuberculosis: an emphasis on improving awareness among caregivers. International Journal of Research in Medical Sciences, $7(11), 4206$.

Jiamsakul, A., Lee, M., Nguyen, K., Merati, T., Cuong, D., Ditangco, R., Yunihastuti, E., Ponnampalavanar, S., Zhang, F., Kiertiburanakul, S., Avihingasanon, A., Ng, O., Sim, B., Wong, W., Ross, J. and Law, M., (2020). Socio-Economic Status And Risk Of Tuberculosis: A Case-Control Study Of HIV-Infected Patients In Asia.

Kanayo, O., Kizito, E. U., \& Udefuna, P. (2013). The challenges and implications of sustainable development in Africa: Policy options for Nigeria. Journal of Economic Cooperation \& Development, 34(4), 77. 
Kirigia, J. M., \& Muthuri, R. D. K. (2016). Productivity losses associated with tuberculosis deaths in the World Health Organization African region. Infectious diseases of poverty, 5(1), 43.

Kuyinu, Y. A., Mohammed, A. S., Adeyeye, O. O., Odugbemi, B. A., Goodman, O. O., \& Odusanya, O. O. (2016). Tuberculosis infection control measures in health care facilities offering tb services in Ikeja local government area, Lagos, South West, Nigeria. BMC infectious diseases, 16(1), 126.

Lar, L. A., Afolaranmi, T. O., Tagarum, Y. O., Uzochukwu, B., \& Zoakah, A. I. (2018). Challenges of Integrated Disease Surveillance response reporing among healthcare Personnel in Mangu, Plateau State, Nigeria. Journal of Public Health and Epidemiology, 7(4), 108-113. Retrieved 03 28, 2019, from https://academicjournals.org/journal/JPHE/article-full-text-pdf/0F27B6651264

Lasebikan, V., \& Ige, M. O. (2016). Suicidality in Tuberculosis Patients and their NonTuberculosis Family Contacts in Nigeria. Mental Health in Family Medicine, 2(1), 100-109. $\quad$ Retrieved $\quad 04 \quad 07, \quad 2019, \quad$ from https://pdfs.semanticscholar.org/127d/5d4ac6729368973396d1af50a32086eab09a.pdf

Mandal, S., Bhatnagar, T., Arinaminpathy, N., Agarwal, A., Chowdhury, A., Murhekar, M., ... \& Sarkar, S. (2020). Prudent public health intervention strategies to control the coronavirus disease 2019 transmission in India: A mathematical model-based approach. Indian Journal of Medical Research, 151(2), 190.

Medecins Sans Frontieres. (2017). TB Policies in 25 Countries; A survey of prevention, testing, treatment, policies and practices. Retrieved 03 31, 2019, from Medecins Sans Frontieres:

http://www.stoptb.org/assets/documents/outofstep/UNOPS_out_of_step_2017_55_on line.pdf

Nasir, I. A., Babyo, A., Emeribe, A. U., \& Sani, N. O. (2015). Surveillance for antibiotic resistance in Nigeria: Challenges and possible solutions. Trends Med. Res, 10, 106-113

Obasanya, J., Abdulrahman, S. T., Oladimeji, O., Lawson, L., Dacombe, R., Chukwueme, N., Cuevas, L. K. (2015). Tuberculosis case detection in Nigeria, the unfinished agenda. Tropical Medicine and International Health, 20(10), 1396-1402. Retrieved 04 08, 2019 
Ogbo, F. A., Ogeleka, P., Okoro, A., Olusany, B. O., Olusanya, J., Ifegwu, I. K., Page, A. (2018). Tuberculosis disease burden and attributable risk factors in Nigeria, 19902016. Tropical Medicine and Health, 46(34), 1-11. Retrieved 03 28, 2019, from https://tropmedhealth.biomedcentral.com/articles/10.1186/s41182-018-0114-9

Onyeonoro, U. U., Chukwu, J. N., Nwafor, C. C., Meka, A. O., Omotowo, B. I., Ogbudebe, C., Oshi, D. C. (2015). Assessment of the quality of tuberculosis surveillance data in six selected states in Southern Nigeria. Annals of Tropical and International Medicine, 8(4), $\quad 94-100 . \quad$ Retrieved $04 \quad 10, \quad 2019, \quad$ from http://www.atmph.org/article.asp?issn=1755-

6783; year $=2015 ;$ volume $=8 ;$ issue $=4$; page $=94 ;$ epage $=100 ;$ aulast $=$ Onyeonoro

Olson Burghardt, Nicole \& Davidow, Amy \& Winston, Carla \& Chen, Michael \& Gazmararian, Julie \& Katz, Dolores. (2012). A national study of socioeconomic status and tuberculosis rates by country of birth, United States, 1996-2005. BMC public health. 12. 365. 10.1186/1471-2458-12-365.

Pareek, M., Greenaway, C., Noori, T., Munoz, J., \& Zenner, D. (2016). The impact of migration on tuberculosis epidemiology and control in high-income countries: a review. BMC Medicine, 14(48). doi:10.1186/s12916-016-0595-5

Parnell, S., van den Bosch, F., Gottwald, T., \& Gilligan, C. A. (2017). Surveillance to inform control of emerging plant diseases: an epidemiological perspective. Annual review of phytopathology, 55, 591-610.

Phalkey, R. K., Yamamoto, S., Awate, P., \& Marx, M. (2015). Challenges with the implementation of an Integrated Disease Surveillance and Response (IDSR) system: a systematic review of the lessons learned. The Journal on Health Policy and Systems Research, 30(1), 131-143. doi:10.1093/heapol/czt097

Rees, E., Ng, V., Gachon, P., Mawudeku, A., McKenney, D., Pedlar, J., ... \& Knox, J. (2019). Risk assessment strategies for early detection and prediction of infectious disease outbreaks associated with climate change. Canada Communicable Disease Report, 45(5), 119-126.

Ukwaja, K. N., Alobu, I., Gidado, M., Onazi, O., \& Oshi, D. C. (2017). Economic support intervention improves tuberculosis treatment outcomes in rural Nigeria. The International Journal of Tuberculosis and Lung Disease, 21(5), 564-570. 
Uplekar, M., Weil, D., Lonnroth, K., Jaramillo, E., Lienhardt, C., Dias, H. M., ... \& Gilpin, C. (2015). WHO's new end TB strategy. The Lancet, 385(9979), 1799-1801.

Uplekar, M., Atre, S., Wells, W. A., Weil, D., Lopez, R., Migliori, G. B., \& Raviglione, M. (2016). Mandatory tuberculosis case notification in high tuberculosis-incidence countries: policy and practice. European Respiratory Journal, 48(6), 1571-1581.

Weizhong Yang, \& Li, Z. (2017). 1.1 Basic Terminologies: Surveillance, Early Warning, and Prediction. In W. Yang, \& R. Read (Ed.), Early Warning for Infectious Disease Outbreak (pp. 361-367). Academic Press. Retrieved 03 29, 2019, from https://www.sciencedirect.com/book/9780128123430/early-warning-for-infectiousdisease-outbreak\#book-info

WHO. (2018, 09 22). Tuberculosis. Retrieved 03 22, 2019, from WHO: https://www.who.int/news-room/fact-sheets/detail/tuberculosis

Yemshanov, D., Haight, R. G., Koch, F. H., Venette, R. C., Swystun, T., Fournier, R. E., ... \& Turgeon, J. J. (2019). Optimizing surveillance strategies for early detection of invasive alien species. Ecological Economics, 162, 87-99. 